\title{
Sensitivity analysis of Aerodynamic Roughness Length on Surface Air Temperature in Eastern China
}

\author{
Jingying Zuo ${ }^{1,2}$, Yuanyuan Qi ${ }^{1}$ \\ 1 State Key Laboratory of Remote Sensing Science, \\ Institute of Remote Sensing and Digital Earth, CAS \\ 2 University of Chinese Academy of Sciences \\ Beijing, China \\ zuojy@irsa.ac.cn
}

\author{
Lixin $\mathrm{Lu}$ \\ Cooperative Institute for Research in the Atmosphere \\ Colorado State University \\ Fort Collins, Colorado, USA \\ lixin.lu@colostate.edu
}

\begin{abstract}
Aerodynamic roughness length is an important surface parameter that influences energy and water exchanges at the land-atmosphere interface, thereby affects regional climate. This study is to investigate the sensitivity of aerodynamic roughness length on climate in Eastern China, which has been experiencing the fast process of urbanization during the past 30 years. Regional Atmospheric Modeling System (RAMS) was used to perform a series of one-year simulations over Eastern China. Six sensitivity tests were conducted by changing vegetation roughness length with $\pm \mathbf{1 0 \%}, \pm \mathbf{5 0} \%, \pm \mathbf{9 0} \%$ and compared to a control run with the model's 'default' parameterization of roughness length. The results show that as the magnitudes of roughness length changes increase, surface air temperature has more distinctive responses. More localized changes occur in the Southeast China than Northeast China, corresponding to the more varied vegetation covers in the south. Besides, surface air temperatures of different land covers have different sensitivity to aerodynamic roughness length. Domain averaged surface air temperature has a negative response to the changes of roughness length. With $90 \%$ of changes in roughness length, for mixed croplands, the differences of surface air temperature between sensitivity and control tests have a positive maximum around 0.7 $\mathrm{k}$, and a negative maximum near $\mathbf{- 0 . 4} \mathbf{~ k}$ in summer. While for short grassland, the positive maximum is around $0.2 \mathrm{k}$ and the negative maximum is about $\mathbf{- 0 . 4} \mathrm{k}$. Thus, the need to realistically represent both the spatial and temporal distribution of vegetation roughness length in regional climate models is highlighted.
\end{abstract}

Key words-Aerodynamic roughness length, RAMS, Regional climate modeling.

\section{INTRODUCTION}

Aerodynamic roughness length $\left(z_{0 m}\right)$ is a key parameter for estimating the energy transfer between land and atmosphere. Previous climate model simulations have shown significant sensitivities to land surfaces parameters. Changes in roughness length have also shown comparable effects [1][2][3]. Sud and Smith's study showed that when land surface roughness length was reduced from $45 \mathrm{~cm}$ to $0.02 \mathrm{~cm}$, the rainfall over the Sahara desert greatly decreased [2]. Reijmer [4] examined the effect of changes in roughness length on the general structure of the lower atmosphere and on the surface energy fluxes over Antarctica. The results indicated that a reduction of $z_{0 m}$ leads to the increase in near-surface wind speed and increase in atmospheric temperatures. Copeland [5] used Regional
Atmospheric Modeling System (RAMS) to assess the impact of a natural versus the current vegetation distribution on climate. The simulated changes in meteorological variables at screen height were closely related to changes in vegetation parameters, including albedo, roughness length, LAI, and fractional vegetation cover. $\mathrm{Lu}$ [6] used RAMS-CENTURY, the coupled atmosphere and ecosystem model, to evaluate the vegetation phenology and land surface heterogeneity's impact on climate and demonstrated a sizable influence on predictions of surface air temperature and precipitation.

$z_{0 m}$ is generally estimated from field experimental data through reference profile measurements. The current practice to input $z_{0 m}$ values in atmospheric modeling is to assign monthly or seasonal climatology values to grid cells by using a simple look-up table method based on land cover classes [7][8] This procedure inevitably ignores the important factors such as variability in plant species within a land class and variability in plant canopy properties including canopy structure, leaf orientation, and the seasonal change in leaf density associated with growth and senescence [9]. With advanced remote sensing development, satellite products of $z_{0 m}$ maps can replace the empirical parameterizations in models, which may improve model simulations. The goal of this study is to investigate the sensitivity of the atmosphere to a series of roughness length changes in Eastern China with a regional climate model system.

\section{EXPERIMENTAL SET-UP}

\section{A. RAMS 6.0}

RAMS 6.0, used for this study, is a three-dimensional, nonhydrostatic atmospheric simulation modeling system consisting of equations of motion, heat, moisture, and mass continuity in a terrain-following coordinate system [10]. The Land Ecosystem-Atmosphere Feedback model (LEAF-3) is a submodel of RAMS that interacts with the modeled atmosphere and provides the lower boundary condition. For the land surface, RAMS uses the "big leaf" approach and BATS classification schemes to represent a layer of vegetation overlying a shaded soil and 18 vegetation classes [11][12][13]. Roughness length, zero plane displacement height, vegetation leaf area index, fractional coverage, transmissivity and albedo are required as input to the land surface scheme in RAMS 6.0. 


\section{B. Grid configaration and control run design}

The model domain used in this study comprises a grid covering Eastern China $\left(25^{\circ} \mathrm{N}-45^{\circ} \mathrm{N}, 110^{\circ} \mathrm{E}-125^{\circ} \mathrm{E}\right)$ at $25-\mathrm{km}$ by $25-\mathrm{km}$ resolution. The pole point for the oblique polar stereographic projection used to define the grid is $17.5^{\circ}$ $\mathrm{N}-32.5^{\circ}$ E. There are 42 vertical levels in the modeled atmosphere, with a layer thickness of $120 \mathrm{~m}$ at the surface, stretching to $1000 \mathrm{~m}$ at the $(100 \mathrm{hPa})$ top of the domain. The model is driven by 6-hourly lateral boundary conditions derived from ECMWF 40 Year atmospheric Re-analysis (ERA-40) Data for a one-year simulation of 2003. The initial atmospheric fields are also provided from the ERA-40 reanalysis. The time step for the atmospheric model integrations is 30 seconds.

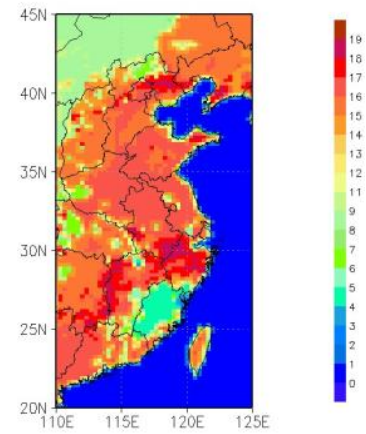

Fig.1 Distribution of vegetation classes used in the grid. The numbers correspond to the following vegetation classes: 0 . Ocean; 1 . Lakes, rivers, streams; 2. Ice cap/glacier; 3.Desert, bare soil; 4. Evergreen needleleaf tree; 5 . Deciduous needleleaf tree; 6 . Deciduous broadleaf tree; 7. Evergreen broadleaf tree; 8. Short grass; 9.Tall grass; 10.Semi-desert; 11. Tundra; 12. Evergreen shrub; 13. Deciduous shrub; 14. Mixed woodland; 15. Crop/mixed farming, C3 grassland; 16. Irrigated crop; 17. Bog or marsh; 18. Wooded grassland; 19.Urban and built up

\section{Surface boundary conditions}

The model vegetation distribution is defined using the USGS(Olson classification, 1992) land-cover classification. With complex topography and soils, the domain includes rather diverse vegetation classes, such as Mixed woodland, various croplands, tundra and evergreen needleleaf trees, as shown in Fig. 1.

In RAMS's submodel LEAF-3, the vegetation roughness length is computed by

$$
z_{0}=H_{v}\left(1-b_{z} e^{-h_{z} L_{T}}\right)
$$

where $b_{z}$ and $h_{z}$ are constant for all vegetation classes. $H_{v}$ is vegetation height, with constant values corresponding to the vegetation classes. The quantities of total leaf area index, $L_{T}$, depend in part on the observed NDVI value, and are given by

$$
L_{T}=L_{G}+L_{D}+L_{S}
$$

where $L_{D}$ is a dead matter area index corresponding to dead matter and $L_{S}$ corresponds to stems and other non-green supportive tissues. The NDVI dataset has been obtained and prepared for RAMS with monthly values defined over the globe at 1/120 degree spacing of latitude and longitude. The practice in LEAF-3 for obtaining roughness length has been to specify them according to vegetation class.

\section{Experiment Design}

In this study, seven experiments were carried out to evaluate the impact of aerodynamic roughness length changes. 1) One control run(CONT) was made, with the roughness length prescribed to follow the standard used in RAMS 6.0.2) Six sensitivity tests of $z_{0 m}$, here called P1, N1, P5, N5, P9, and N9 respectively were conducted in this study by changing vegetation roughness length with $\pm 10 \%, \pm 50 \%, \pm 90 \%$ of its default values. Seasonal and regional comparisons were made between sensitivity results and control run to evaluate the sensitivity of 2-m air temperature to the changes of $z_{0 m}$.

\section{RESULTS}

\section{A. Model performance: control run compared with observations}

To validate RAMS and investigate the relationship between the vegetation growth cycle and climate, control run results were compared with surface meteorological observations. Station observation data of 2003 were obtained and gridded onto the 25-km RAMS grid using an objective analysis scheme following Cressman (1959).

The modeled monthly averaged 2-m air temperatures are compared with measurements in Fig. 2 and Fig. 3. 2-m temperature is reasonably well modeled with similar patterns of surface observation temperatures in four different seasons. The correlations between observations and simulated temperatures in three main urban areas (Jing Jing Tang, Yangzte River delta, and Zhu Jiang Delta) are over 0.95. The above results show that RAMS6.0 can well capture the seasonal and spatial variations of $2 \mathrm{~m}$ air temperature.
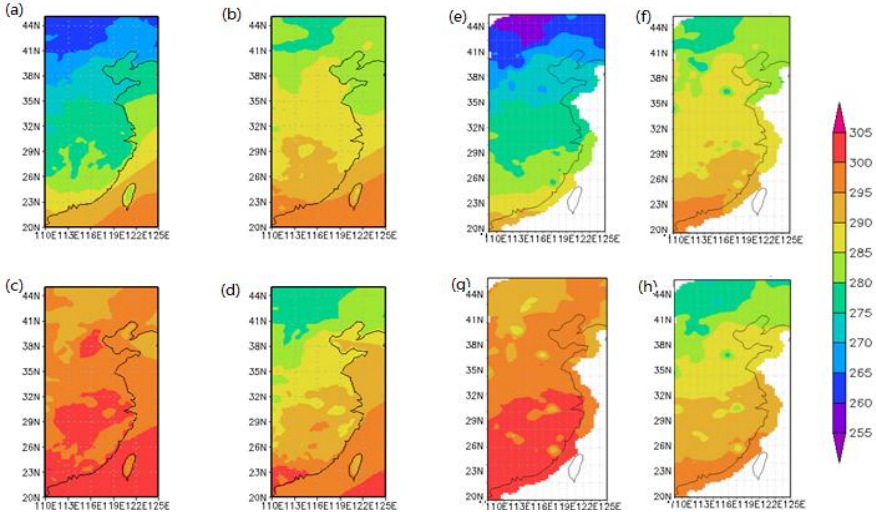

Fig.2 Seasonal variation comparison of simulated 2-m temperature with stations observations over Eastern China, simulated: (a) December-February (DJF), (b) March-May (MAM), (c) June-August(JJA), (d)SeptemberNovember (SDN); observations: (e) DJF, (f) MAM, (g) JJA, (h)SDN 


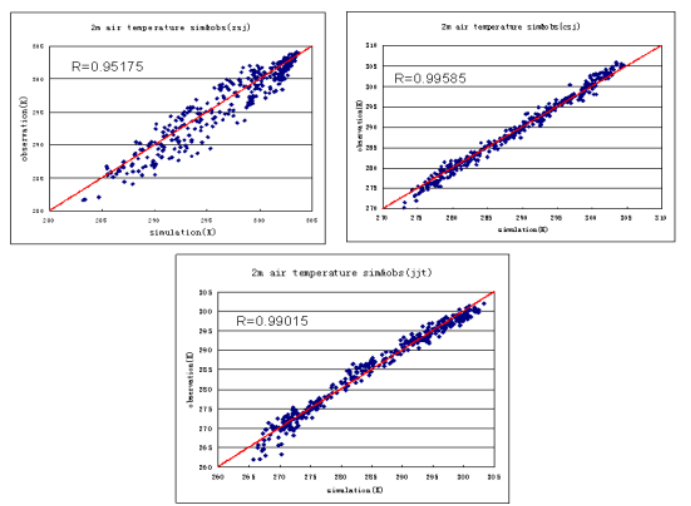

Fig. 3 Comparison of domain averaged 2-m air temperature with station observations at three Eastern China's main urban areas (JJT,ZSJ,CSJ)

\section{B. Spatial varions in roughness length}

The distribution of roughness length in control run is shown in Fig.4. The values range from 0 to approximately $2.4 \mathrm{~m}$. In RAMS, $z_{0 m}=0.02 \mathrm{~cm}$ is taken as the surface roughness of the oceans, $z_{0 m}=0.05 \mathrm{~m}$ is set for bare soil.

In the model, $z_{0 m}$ values over $2.2 \mathrm{~m}$ are found over south east part of the land, with needle leaf tree covered, where is located the hill areas with its topographical height at the range of 400 to $600 \mathrm{~m}$ above sea level. The smallest $z_{0 m}$ over Eastern China is on the northwest corner, covered by short grassland on the height of over $1000 \mathrm{~m}$ above sea level. This orography is expected to have a large impact on the resolved air flow. In between are mostly mixed croplands with roughness length ranging from $0.1-0.15 \mathrm{~m}$. These three parts, with quite distinguished land characteristics can be expected to have different impacts on climate.

$z_{0 m}$ in RAMS depends on LAI also has seasonal variations.

Fig.5 shows the seasonal variations of $z_{0 m}$ for mixed croplands and short grassland. Owing to the growing season of vegetation, LAI is larger in summer and smaller in winter; and roughness lengths for different land cover also shares the same pattern. Roughness length for grassland ranges from 0.44 to $0.443 \mathrm{~m}$, while that of mixed croplands ranges from 0.6 to $1.3 \mathrm{~m}$.
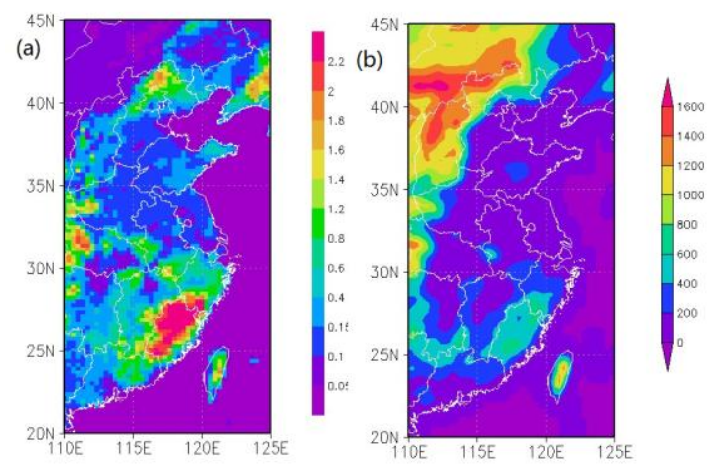

Figure 4. a) Default surface roughness length for momentum $\left(z_{0 m}\right)$ in control run; b) Topography of Eastern china (m)

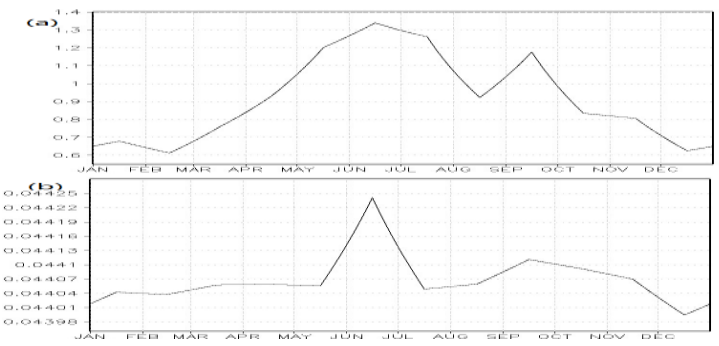

Fig. 5 Seasonal variantions of roughness length for (a) mixed croplands; (b) short grassland

\section{Sensitivity of 2-m air temperature}

Roughness length changes have a direct impact on the magnitude of the sensible heat fluxes and latent heat fluxes, and an indirect effect by changing the near-surface wind speed, temperature and specific humidity gradients. The changes in the advection patterns of heat, near-surface stability and small variations in the large-scale circulation patterns affect the surface air temperature. Fig. 6 presents the differences of domain averaged daily 2-m air temperature between sensitivity tests and control run. The results show that 1) The increase of $z_{0 m}$ leads to the decrease of 2-m air temperature, while the decrease of $z_{0 m}$ results in the opposite. The larger magnitude of $z_{0 m}$ changes leads to the larger responses of $2-\mathrm{m}$ air temperature. Such feedback is similar to those presented by Reijmer, who studied the effect of changes in roughness length on the general structure of the lower atmosphere and the surface energy fluxes over Antarctica [4]. A reduction of $z_{0 m}$ results in the increase in near-surface wind speed and decrease in resistance of heat advection, and as a result, the surface temperatures on average decrease while atmospheric temperatures increase. 2) More localized changes occur in the Southeast China than Northeast China, as there are more varied vegetation covers in the south, with evergreen needleleaf tree, wooded grassland, mixed woodland, deciduous shrub of relatively large $z_{0 m}$ values on the domain area
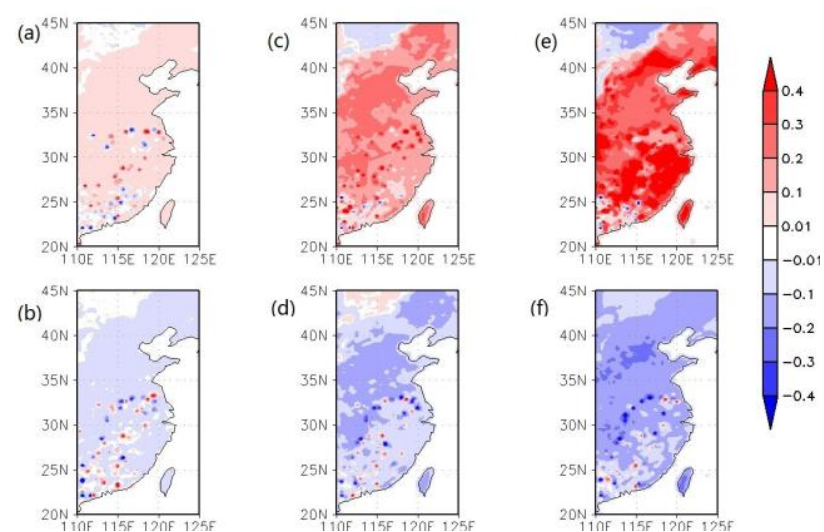

Fig. 6 Differences of domain averaged daily $2 \mathrm{~m}$-air temperature between sensitivity tests and control run for 2003 calculated by RAMS (a) N1-CONT, (b) P1-CONT, (c) N5-CONT, (d) P5-CONT, (e) N9-CONT; (f) P9-CONT.

As can be seen in Fig.7 and table 1, the effects of roughness length changes on 2-m air temperature of different land covers share similar patterns, with larger differences in summer and smaller differences in winter. For mixed croplands, the differences between sensitivity and control run have a positive 
maximum value of about $0.7 \mathrm{k}$, and a negative maximum value of about $-0.4 \mathrm{k}$. While for short grassland, the positive maximum is around $0.2 \mathrm{k}$ and the negative maximum is approximately $-0.4 \mathrm{k}$. This reflects that $2-\mathrm{m}$ air temperature for croplands are more sensitive to the increase of $z_{0 m}$ while for grasslands, surface air temperature is prone to be sensitive to the decrease of $z_{0 m}$. For the whole domain of Eastern China, 2-m air temperature is more sensitive to the increase of $z_{0 m}$.

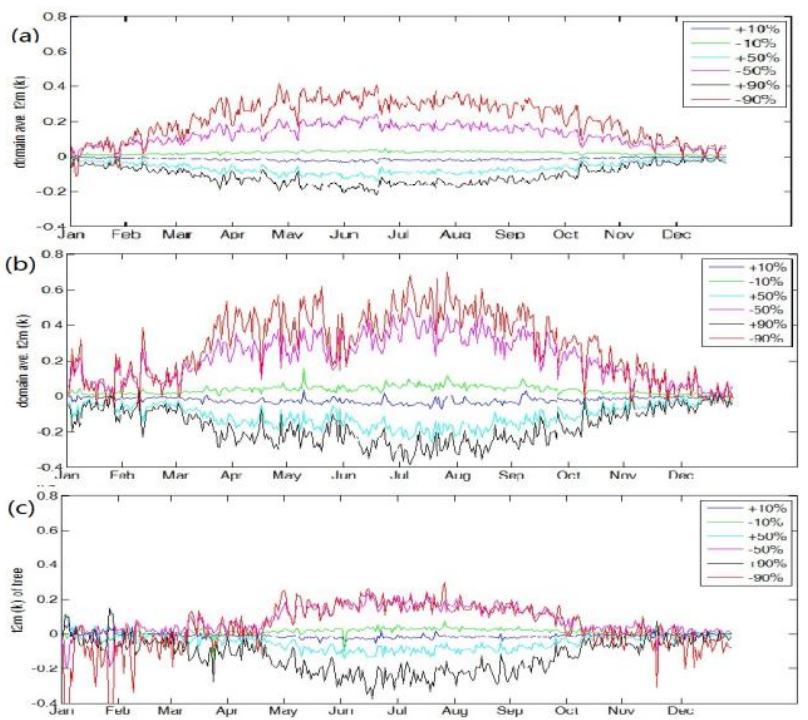

Fig. 7 Domain averaged 2-m air temperature (a) whole domain; (b) mixed croplands; (c) short grassland

TABLE I. STATISTICS OF THE COMPARISON BETWEEN SENSITIVITY AND CONTROL RUNS 'S MODELED 2-MTEMPERATURE (T2M ). BIAS IS THE AVERAGE DIFFERENCE (SENSITIVITY - CONTROL), STD IS THE STANDARD DEVIATION OF THE DIFFERENCE

\begin{tabular}{|l|l|l|l|l|l|l|}
\hline \multirow{2}{*}{$\begin{array}{c}\text { Experi } \\
\text { ment }\end{array}$} & \multicolumn{6}{|c|}{ T2m } \\
\hline & \multicolumn{2}{|c|}{ Domain ave. } & \multicolumn{1}{c|}{ Short Grass } & \multicolumn{2}{c|}{ Mixed crop } \\
\cline { 2 - 7 } & bias & std & bias & std & bias & std \\
\hline P1 & -0.013 & 0.078 & -0.0032 & 0.0173 & -0.0275 & 0.0202 \\
\hline N1 & 0.016 & 0.057 & 0.0012 & 0.0228 & 0.0244 & 0.0189 \\
\hline P5 & -0.054 & 0.074 & -0.0144 & 0.0361 & -0.1038 & 0.0507 \\
\hline N5 & 0.105 & 0.126 & 0.0101 & 0.0520 & 0.1923 & 0.0962 \\
\hline P9 & -0.089 & 0.092 & -0.0977 & 0.0860 & -0.1668 & 0.0757 \\
\hline N9 & 0.180 & 0.208 & 0.0628 & 0.1492 & 0.2624 & 0.1713 \\
\hline
\end{tabular}

\section{CONCLUSION AND PROSPECT}

Our sensitivity tests show that $z_{0 m}$ affects 2-m air temperature mainly in the local scale, especially in the south part of Eastern China. Different land covers have different responses to the changes of $z_{0 m}$. For example, mixed crop lands and grasslands show the opposite sensitivities to the changes of $z_{0 m}$.

With current empirical parameterizations of roughness length in the model, uncertainty and limitations are inevitably embedded and therefore affect the simulation of atmosphere. So a temporally and spatially continuous data set of roughness length is necessary to improve the climate modeling.

The seasonality of the changes in other climate variables such as precipitation, wind speed and surface fluxes will be explored for further understanding the impact of $z_{0 m}$ on climate and weather. Moreover, the relative influence of different land-cover biophysical parameters such as albedo and evapotranspiration, on the climate modeling will be assessed in the future studies.

\section{ACKNOWLEDGMENT}

This research was partially supported by a National Basic Research Program of China (973 Program, Grant No. 2010CB428502) and National Natural Science Foundation of China (Grant No. 40930530, 41075112). The writers express their great appreciation to the anonymous referees for their valuable suggestions.

\section{REFERENCES}

[1] Shukla, J., and Y. Mintz, 1982: Influence of land-surface evapotranspiration on the earth's climate. Science, 215, 14981501.

[2] Sud, Y. C., and W. E. Smith, 1985: Influence of surface roughness of deserts on the July circulation. Bound.-Layer Meteor., 33, 15-49.

[3] Meehl, G. A., and W. M. Washington, 1988: Comparison of soil moisture sensitivity in two global climate models. J. Atmos. Sci., 45, 1476-1492.

[4] Reijmer, C.H., E. Van Meijaard, and M.R. Van Dan Broeke, 2004: Numerical studies with a regional atmospheric climate model based on changes in the roughness length for momentum and heat over Antactica. Boundary-Layer Meteorol., 111,469486

[5] Copeland, J. H., R. A. Pielke, and T. G. F. Kittel, 1996: Potential climatic impacts of vegetation change: A regional modeling study. J. Geophys. Res., 101, 7409-7418

[6] Lu, L.,R. A. Pielke, G. E. Liston, W. J. Parton, D. Ojima, and M. Hartman, 2001: Implementation of a two-way interactive atmospheric and ecological model and its application to the central United States. J. Climate, 14, 900-919.

[7] Garrat, J.R., 1992, The atmospheric boundary layer. Cambridge: Cambridge University Press, 336 pp.

[8] Grell, G. A., J. Dudhia, and D. R. Stauffer, 1995: A description of the fifth generation Penn State/NCAR mesoscale model (MM5). NCAR Tech. Note NCAR/TN-398+STR, 138 pp.

[9] Jasinski, M.F., Borak, J., and Crago, R. 2005. Bulk surface momentum parameters for satellite derived vegetation fields. Agricultural and Forest Meteorology, Vol. 133, pp. 55-68. doi: 10.1016/j.agrformet.2005.07.017.

[10] Pielke, R. A., and Coauthors, 1992: A comprehensive meteorological modeling system-RAMS. Meteor. Atmos. Phys., 49, 69-91.

[11] Avissar, R.,P. Avissar, Y. Mahrer, and B. A. Bravdo, 1985: A model to simulate response of plant stomata to environmental conditions. Agric. For. Meteor., 34, 21-29.

[12] Lee, T. J., 1992: The impact of vegetation on the atmospheric boundary layer and convective storms. Ph.D. dissertation, Dept. of Atmospheric Science Paper 509, Colorado State University, $137 \mathrm{pp}$.

[13] Dickinson, R. E., J. Jaeger, W. M. Washington, and R. Wolski, 1981:Boundary subroutine for the NCAR global climate model.NCAR Tech. Note 17311A, 75 pp. Science, 1989. 